\title{
PERBAIKAN SISTEM PENGENDALIAN KUALITAS PT. POS INDONESIA (PERSERO) AMBON UNTUK MENCAPAI TARGET DISTRIBUSI DIBAGIAN EKSPEDISI MENGGUNAKAN METODE SIX SIGMA
}

\author{
M. Tukan \\ Program Studi Teknik Industri, Fakultas Teknik Universitas Pattimura, Ambon \\ Meiyanti Chantika Pattiasina \\ Program Studi Teknik Industri, Fakultas Teknik Universitas Pattimura, Ambon
}

\begin{abstract}
ABSTRAK
PT. Pos Indonesia (Persero) merupakan salah satu perusahaan yang bergerak dibidang jasa dalam mendistribusikan kiriman. Bagian ekspedisi (antaran) merupakan bagian terakhir dalam proses distribusi kiriman, harus mendapatkan perhatian khusus sehingga dapat mengatasi ketidakcapaian target kerja yaitu SWP (Standar Waktu Penyerahan) yang diakibatkan karena kegagalan yang sering terjadi dalam proses distribusi kiriman. Masalah ini dapat diatasi dengan melakukan perbaikan dalam proses distribusi. Six Sigma merupakan salah satu metode dalam sistem pengendalian kualitas. Metode Six Sigma adalah proses perbaikan secara terus menerus untuk mengurangi tingkat kecacatan/kegagalan. Pada penelitian ini dilakukan perhitungan untuk mengukur keberhasilan dan kegagalan dalam proses distribusi kiriman di bagian ekspedisi PT. Pos Indonesia (Persero) Ambon. Dari hasil pengolahan data menggunakan six sigma menunjukkan terdapat 3 jenis kegagalan dalam proses distribusi yaitu antar ulang, salah salur, dan kirim kembali dengan jenis kegagalan yang paling banyak ialah kiriman antar ulang dengan presentasi sebesar 85\% yang ditinjau dari kecacatan yang dimiliki selama 5 bulan dari bulan januari-mei 2018 sebesar 8.920 kiriman, CTQ (critical to quality) yang dimiliki yaitu 3, nilai DPMO sebesar 32.851 sehingga nilai sigma yang didapat sebesar 3,34.
\end{abstract}

Kata Kunci: Target Distribusi, Pengendalian Kualotas, Six Sigma

\begin{abstract}
PT. Pos Indonesia (Persero) is one of the state-owned enterprises for serving distribution. The expedition department is the final department in distribution process chain. Extra concern is needed in the department to cope unachievable target that is delivery time standard. This situation is caused by delivery process failure. Improving in the distribution process can solve the problem. Six Sigma is one of quality control that is continuous improvements process in minimizing defect or failure. The result shows that six sigma found 3 failure in the distribution process those are redistribution, wrong channel and redelivery. The most defects is redistribution $85 \%$ or 8920 delivery product that is observed for five months from January to May 2018. The number of critical to quality is 3, the DPMO value is 32.851 and sigma vaue is 3.34..
\end{abstract}

Keywords: Distribution target, quality control, six sigma

\section{PENDAHULUAN}

PT. Pos Indonesia (Persero) adalah salah satu perusahaan milik pemerintah yang telah lama berdiri dan memiliki sejarah panjang, dimana PT. Pos Indonesia (Persero) dalam perjalanannya telah beberapa kali mengalami perubahan status mulai dari Jawatan PTT (Post, Telegraph, dan Telephone). Perubahan dari tahun ke tahun mengikuti perkembangan zaman. Selama 17 tahun berstatus Perum, maka juni 1995 berubah menjadi Perseroan Terbatas dengan nama PT. Pos Indonesia (Persero) sampai sekarang ini. (Aji, 2017).

PT. Pos Indonesia (Persero) selalu berusaha untuk memenuhi kepuasaan publik. Dengan berjalannya waktu PT. Pos Indonesia (Persero) kini telah mampu menunjukkan kreatifitasnya dalam pengembangan bidang perposan Indonesia dengan memanfaatkan insfrastruktur jejaring yang dimilikinya yang 
mencapai sekitar 24 ribu titik layanan yang menjangkau 100 persen kota/kabupaten, hampir 100 persen kecamatan dan 42 persen kelurahan/desa, dan 940 lokasi transmigrasi terpencil di Indonesia. Seiring dengan perkembangan informasi, komunikasi dan teknologi, jejaring Pos Indonesia sudah memiliki lebih dari 3.800 Kantorpos online, serta dilengkapi electronic mobile pos di beberapa kota besar. (Aji, 2017)

Setiap perusahan memiliki strategi untuk mendapatkan keuntungan bagi perusahaan. Sama halnya dengan PT. Pos Indonesia (Persero) dalam meningkatkan keuntungan pada perusahan dilakukan dengan berbagai strategi. Strategi-strategi yang diterapkan yaitu: Menjual produk sesuai dengan standar mutu yang telah ditetapkan, membuka layanan konsumen dan menindaklanjuti keluhan konsumen tanpa melakukan diskriminasi terhadap konsumen, melakukan promosi yang berkesinambungan secara sehat, fair, jujur, tidak menyesatkan serta diterima oleh norma-norma masyarakat, melakukan sertifikasi mutu melalui sistem manajemen mutu, melakukan perbaikan dibidang Operasi, sarana dan prasarana produk sesuai dengan kemampuan Perusahaan, memberikan layanan purna jual yang sesuai.

PT. Pos Indonesia (Persero) memiliki target kerja yang ditetapkan. Namun instansi atau bagian pada perusahan ini memiliki target yang berbeda-beda sesuai dengan tugas dan tanggung jawab pada instansi masing-masing, dari beberapa instansi yang ada namun penulis tertarik untuk meneliti pada bagian/divisi ekpedisi (antaran) karena pada bagian/divisi tersebut memiliki tanggung jawab yang besar dimana kepercayaan publik terdapat pada pekerja di bagian ekspedisi (antaran), serta akredibilitas perusahaan tergantung pada pekerja dibagian ekspedisi (antaran). Pada bagian ini, tugas dan tanggung jawab utamanya adalah melakukan antaran paket ke tempat tujuan dengan aman. Target atau sasaran pada bagian ekspedisi adalah tercapainya SWP (Standar Waktu Penyerahan). Proses pengantaran menggunakan target SWP terbagi dalam 3 bagian yaitu Pos Express (kiriman dengan jangka waktu 1 hari), Pos Kilat Khusus (Kiriman dengan jangka waktu 3-4 hari) dan Pos Biasa (kiriman dengan jangka waktu 1 minggu lebih). Dalam bagian ekspedisi (antaran) memiliki 10 karyawan dengan tugas dan tanggung jawab masing-masing, yaitu; 1 orang Manajer, 1 orang Mandor dan 8 Petugas Antaran. Daerah-daerah yang dijangkau PT. Pos Indonesia (Persero).

Dalam berbagai usaha yang djalankan tentu ada saja hal maupun hambatan yang terdapat di perusahaan. Hal-hal tersebut dipengaruhi oleh berbagai macam faktor, sehingga perlu adanya perbaikan untuk mengatasi hambatan yang ada. Hambatan pada bagian ekspedisi (antaran) adalah sering tidak tercapainya target sesuai dengan target yang ditetapkan. Tidak tercapainya target dilihat dari banyaknya kiriman yang tidak berhasil diantar sampai pada tempat tujuan dengan tepat waktu dan dalam kondisi yang aman. Kiriman yang datang setiap hari pada PT. Pos Indonesia (Persero) Ambon dan diantar ke tempat tujuan tidak pernah $100 \%$ terantar ke tangan penerima tepat dengan waktu penyerahan. Kiriman yang tidak sampai dengan tepat waktu maka dikatakan gagal, karena tidak sesuai dengan target standar waktu penyerahan (SWP). Tidak tercapainya target dapat dilihat dari data perhitungan berhasil dan gagal dalam proses distribusi kiriman yang diantar. Berikut terdapat data proses distribusi kiriman pada bulan Januari - Mei 2018 yang didapatkan dari PT. Pos Indonesia (Persero) Ambon. Pada bulan Januari kiriman yang masuk sebanyak 12.957 kiriman, berhasil diantar sebanyak 11.336 kiriman, gagal antar sebanyak 1.621 kiriman. Pada bulan Februari kiriman yang masuk sebanyak 17.621 kiriman, berhasil diantar sebanyak 16.176 kiriman, gagal antar sebanyak 1.445 kiriman. Pada bulan maret kiriman yang masuk sebanyak 20.911 kiriman, berhasil diantar sebanyak 19.030 kiriman, gagal antar sebanyak 1.881 kiriman. Pada bulan april kiriman yang masuk sebanyak 23.836 kiriman, berhasil diantar sebanyak 21.597kiriman, gagal antar sebanyak 2.239 kiriman. Dan pada bulan mei kiriman yang masuk sebanyak 15.185 kiriman, berhasil diantar sebanyak 13.451 kiriman, gagal antar sebanyak 1.734 kiriman. Tidak tercapainya target SWP dipengaruhi dengan berbagai macam faktor baik internal maupun eksternal, beberapa contoh faktor kegagalan yaitu alamat tidak jelas, penerima tidak dikenal, rumah kosong, kiriman rusak.

Kualitas adalah segala sesuatu yang memenuhi keinganan atau kebutuhan pelanggan (Gaspersz, 2006:1). Melalui pengendalian kualitas (quality control) diharapkan bahwa perusahaan dapat meningkatkan efektifitas pengendalian dalam mencegah terjadinya produk cacat (defect prevention). Dibandingkan dengan perusahan yang bergerak dibidang jasa milik negara ini, produk dikatakan cacat apabila paket tidak berhasil diantar yang dipengaruhi oleh beberapa faktor tertentu sehingga tidak tercapainya target sesuai dengan apa yang diharapkan, segingga dilakukan penelitian tentang perbaikan sistem pengendalian kualitas untuk mencapai target distribusi. Studi kasus pada PT. Pos Indonesia Persero (Ambon) terkhususnya pada bagian ekspedisi (antaran). Metode pemecah masalah yang digunakan yaitu metode six sigma karena Six sigma merupakan cara pendekatan kualitas terhadap Total Quality Management (TQM), sehingga dapat membantu penulis dalam melihat pengaruh pengendalian kualitas terhadap pencapaian target distribusi pada bagian ekspedisi (antaran). 
Tujuan dari penelitian ini adalah mengidentifikasi proses distribusi kiriman PT. Pos Indonesia (Persero) Ambon dalam pencapaian target distribusi, mengukur tingkat kegagalan pada proses distribusi kiriman PT. Pos Indonesia (Persero) Ambon dan memberikan solusi atau upaya perbaikan proses distribusi kiriman PT. Pos Indonesia (Persero) Ambon dalam pencapaian target dibagian ekspedisi dengan menggunakan metode Six Sigma.

\section{LANDASAN TEORI}

\section{Pengendalian Kualitas}

Istilah kualitas sangat penting bagi suatu organisasi atau perusahaan. Menurut Feigenbaun, A.V (1961) kata kualitas yang berorientasi pada kepuasan konsumen tidak harus mempunyai arti "yang terbaik" dalam dunia industri, melainkan kualitas berarti lebih baik dalam memuaskan kebutuhan konsumen. Sedangkan dalam orientasi pada proses produksi kualitas adalah kesesuaian spesifikasi dari desain produk yang telah ditetapkan produsen. Ada beberapa alasan perlunya kualitas bagi suatu organisasi menurut russel (1996) dikutip dari bukunya Dorothea (2003), mengidentifikasi enam peran pentingnya kualitas yaitu:

1. Meningkatkan reputasi perusahaan

2. Menurunkan biaya

3. Meningkatkan pangsa pasar

4. Dampak internasional

5. Adanya pertanggungjawaban produk

6. Untuk penampilan produk mewujudkan kualitas yang dirasakan penting

Istilah dari kualitas memiliki pengertian yang berbeda-beda sesuai dengan penerapannya dari berbagai dimensi, sehingga kualitas memiliki banyak presepsi. Defenisi kualitas berdasarkan pendapat dari beberapa ahli, antara lain:

1. Conformance to requirements (Crosby, 1979)

2. Fitness for use (Juran, 1979)

3. Continual improvements (Deming, 1982)

4. As defined by the customers (Ford, 1984, 1990)

5. Loss to society (Taguchi, 1987)

6. Six sigma (Harry and Stward [Motorola], 1988)

7. Zero defects (Crosby, 1987)

Pengendalian kualitas dalam arti menyeluruh adalah Pengawasan mutu yang merupakan usaha untuk mempertahankan mutu kualitas dari barang yang dihasilkan,agar sesuai dengan spesifikasi produk yang telah ditetapkan berdasarkan kebijaksanaan pimpinan perusahaan. Pengendalian kualitas adalah penggunaan teknik dan kegiatan untuk mencapai,mempertahankan dan meningkatkan kualitas dari sebuah produk atau jasa. Dengan kata lain pengendalian kualitas merupakan usaha untuk mempertahankan dan meningkatkankualitas dari produk yang dihasilkan, agar sesuai dengan spesifikasi produk yang telah ditetapkan berdasarkan kebijaksanaan pimpinan perusahaan (Pavletic dkk, 2008). Berdasarkan pengertian di atas, maka dapat disimpulkan bahwa pengendalian kualitas adalah suatu teknik dan aktivitas/tindakan yang telah disusun dan direncanakan dan dilakukan untuk mempertahankan serta meingkatkan kualitas suatu produk jasa dan produk manufaktur agar sesuai dengan standar target yang telah ditetapkan dan dapat memenuhi kepuasan konsumen.

Tujuan dari pengendalian kualitas menurut Sofjan Assauri (1998:210) adalah :

1. Agar barang hasil produksi dapat mencapai standar kualitas yang telah ditetapkan.

2. Mengusahakan agar biaya inspeksi dapat menjadi sekecil mungkin.

3. Mengusahakan agar biaya desain dari produk dan proses dengan.menggunakan kualitas produksi tertentu dapat menjadi sekecil mungkin

4. Mengusahakan biaya produksi dapat menjadi serendah mungkin.

Tujuan utama pengendalian kualitas adalah untuk mendapatkan jaminan bahwa kualitas produk atau jasa yang dihasilkan sesuai dengan standar kualitas yang telah ditetapkan dengan mengeluarkan biaya yang ekonomis atau serendah mungkin. Menurut Douglas C. Montgomery (2001), faktor-faktor yang mempengaruhi pengendalian kualitas yang dilakukan perusahaan adalah:

1. Kemampuan proses. Batas-batas yang ingin dicapai haruslah disesuaikan dengan kemampuan proses yang ada. Tidak ada gunanya mengendalikan suatu proses dalam batas-batas yang melebihi kemampuan atau kesanggupan proses yang ada.

2. Spesifikasi yang berlaku, hasil produksi yang ingin dicapai harus dapat berlaku, bila ditinjau dari segi kemampuan proses dan keinginan atau kebutuhan konsumen yang ingin dicapai dari 
hasil produksi tersebut. Dapat dipastikan dahulu apakah spesifikasi tersebut dapa tberlaku sebelum pengendalian kualitas pada proses dapat dimulai.

3. Tingkat ketidaksesuaian yang dapat diterima. Tujuan dilakukan pengendalian suatu proses adalah dapat mengurangi produk yang berada di bawah standar seminimal mungkin. Tingkat pengendalian yang diberlakukan tergantung pada banyaknya produk yang berada dibawah standar

4. Biaya kualitas, sangat mempengaruhi tingkat pengendalian dalam menghasilkan produk dimana biaya mempunyai hubungan yang positif dengan terciptanya produk yang berkualitas.

\section{Distribusi}

Distribusi adalah salah satu elemen dari marketing mix. Distribusi dapat diartikan sebagai kegiatan pemasaran yang berusaha memperlancar dan mempermudah penyampaian barang dan jasa dari produsen kepada konsumen. Distribusi merupakan kegiatan yang sangat penting dalam sistem pemasaran karena distribusi yang ef ektif dan efisien maka barang akan cepat dipasarkan dan selanjutnya akan dibeli dan dikonsumsi oleh konsumen. Semua perusahaan perlu melakukan fungsi distribusi dan hal ini sangat penting bagi pembangunan perekonomian masyarakat karena bertugas menyampaikan barang dan jasa yang diperlukan oleh konsumen. (Ardiyanta,2013)

Saluran distribusi menurut Fandy Tjiptono, Gregorius Chandra dan Dadi Andriana (2008 : 588) didefinisikan sebagai berikut, bahwa "saluran distribusi merupakan serangkaian partisipasi organisasional yang melakukan semua fungsi dibutuhkan untuk menyampaikan produk/jasa dari penjual ke pembeli akhir. Menurut Kotler (1985:3) mendefinisikan saluran distribusi sebagai himpunan perusahaan dan perorangan yang mengambil alih hak, atau membantu dalam pengalihan hak atas barang atau jasa tertentu selama barang atau jasa tersebut berpindah dari produsen ke konsumen. Sedangkan Basu Swastha DH (2009:190) mendefinisikan saluran distribusi untuk suatu barang adalah saluran yang digunakan oleh produsen untuk menyalurkan barang tersebut dari produsen sampai ke konsumen atau pemakai industri. Saluran distribusi ini merupakan suatu struktur yang menggambarkan alternatif saluran yang dipilih, dan menggambarkan situasi pemasaran yang berbeda oleh berbagai macam perusahaan atau lembaga usaha.

Menurut Fandy Tjiptono, Gregorius Chandra, dan Dadi Andriana (2008) ada beberapa saluran distribusi yang digunakan perusahaan adalah sebagai berikut :

1. Distribusi Eksklusif

2. Distribusi Intensif

3. Distribusi Selektif

\section{Six Sigma}

Sigma $(\sigma)$ merupakan sebuah abjad Yunani yang menunjukkan standar deviasi dari suatu proses. Standar deviasi mengukur variasi atau jumlah persebaran suatu rata-rata proses. Nilai sigma dapat diartikan seberapa sering cacat yang mungkin terjadi. Jika semakin tinggi tingkat sigma maka semakin kecil toleransi yang diberikan pada kecacatan sehingga semakin tinggi kapabilitas proses, dan hal itu odikatakan semakin baik. Dalam esensinya, Six Sigma menganjurkan bahwa terdapat hubungan yang kuat antara cacat produk dan produk yang dihasilkan, reliability, costs, cycle time, inventory, schedule, dll. Bila jumlah cacat yang meningkat, maka jumlah sigma akan menurun. Dengan kata lain, dengan nilai sigma yang lebih besar maka kualitas produk akan lebih baik.

Konsep Six Sigma merupakan perbaikan secara terus menerus (continous improvement) untuk mengurangi cacat adalah dengan meminimalisasi variasi yang terjadi pada proses produksi. Menurut Gasperz (2002) ada enam aspek yang perlu diperhatikan dalam penerapan konsep Six Sigma dibidang manufactur:

1. identifikasi karakteristik produk yang akan memuaskan pelanggan (sesuai kebutuhan dan ekspektasi pelanggan),

2. mengklasifikasikan karakteristik kualitas yang akan dianggap sebagai CTQ (Critical to Quality),

3. menentukan apakah setiap CTQ itu dapat dikendalikan melalui pengendalian material, mesin, proses-proses kerja, dan lain-lain.

4. menentukan batas maksimum toleransi untuk setiap CTQ sesuai yang dinginkan pelanggan (menentukan nilai Upper Specification Limit dan Lower Specification Limit dari setiap CTQ),

5. menentukan maksimum variasi proses untuk setiap CTQ (menentukan nilai maksimum standart deviasi untuk setiap CTQ),

6. mengubah desain produk dan atau proses sedemikian rupa agar mampu mencapai nilai target Six Sigma yang berarti memiliki indeks kemampuan proses, Cp minimum sama dengan dua $(\mathrm{Cp} \geq 2)$ atau 3,4 DPMO 
Six Sigma menggunakan alat statistik untuk mengidentifikasi beberapa faktor vital, Siklus DMAIC merupakan proses kunci untuk peningkatan secara kontinyu menuju target Six Sigma. DMAIC dilakukansecara sistematik berdasarkan ilmu pengetahuan dan fakta (systematic, scientific, and fact based). Berikut ini adalah tahapan dalam siklus DMAIC dan langkah-langkah yang harus dilaksanakan pada setiap tahap:

A. Define (D)

Tahap Define merupakan langkah operasional pertama dalam program peningkatan kualitas Six Sigma. Dalam tahap Define dilakukan identifikasi proyek yang potensial, mendefinisikan peran orang-orang yang terlibat dalam proyek Six Siqma, mengidentifikasi karakteristik kualitas kunci (CTQ) yang berhubungan langsung dengan kebutuhan spesifik dari pelanggan dan menentukan tujuan.

B. Measure (M)

Measure merupakan langkah operasional kedua dalam program peningkatan kualitas Six Sigma, terdapat beberapa hal pokok yang harus dilakukan yaitu:

1. Melakukan dan mengembangkan rencana pengumpulan data yang dapat dilakukan pada tingkat proses, dan/atau output.

2. Mengukur kinerja sekarang (current performance) untuk ditetapkan sebagai baseline kinerja pada awal proyek Six Sigma.

C. Analyze (A)

Merupakan langkah operasional ketiga dalam program peningkatan kualitas Six Sigma. Sebenarnya target dari program Six Sigma adalah membawa proses industri pada kondisi yang memiliki stabilitas (stability) dan kemampuan (capability), sehingga mencapai tingkat kegagalan nol (zero defect oriented).

D. Improve ( I )

Setelah sumber-sumber dan akar penyebab permasalahan kualitas teridentifikasi, maka perlu dilakukan penentapan rencana tindakan (action plan) untuk melaksanakan peningkatan kualitas Six Sigma, yaitu dengan tools: Failure Mode and Effect Analysis (FMEA) yang mendiskripsikan tentang alokasi sumber- sumber daya serta prioritas dan atau alternatif yang dilakukan dalam implementasi dari rencana itu.

E. Control ( C )

Merupakan tahap operasional terakhir dalam proyek peningkatan kualitas Six Sigma. Pada tahap ini prosedur-prosedur serta hasil-hasil peningkatan kualitas didokumentasikan untuk dijadikan pedoman kerja standart guna mencegah masalah yang sama atau praktek-praktek lama terulang kembali, kemudian kepemilikan atau tanggung jawab ditransfer dari tim Six Sigma kepada penanggung jawab proses, dan ini berarti proyek Six Sigma berakhir pada tahap ini.

\section{METODE PENELITIAN}

\section{Variabel dan Definisi Operasional}

Variabel keputusan dapat dinotasikan dengan lambang X. Yang termasuk dalam indikator variabel keputusan dalam penilitian adalah sebagai berikut :

a. Data Distribusi Kiriman $\left(\mathrm{X}_{1}\right)$

b. Data Kegagalan Distribusi $\left(\mathrm{X}_{2}\right)$

Variabel keputusan merupakan suatu indikator untuk mencapai variabel tujuan. Yang mana variabel tujuan adalah Target Distribusi Pada PT. Pos Indonesia (Persero) Ambon.

\section{Metode Analisa Data}

Metode dalam penelitian ini bersifat kuantitatif dengan menggunakan metode Six Sigma untuk Berikut ini merupakan flowchart dari penelitian ini. 


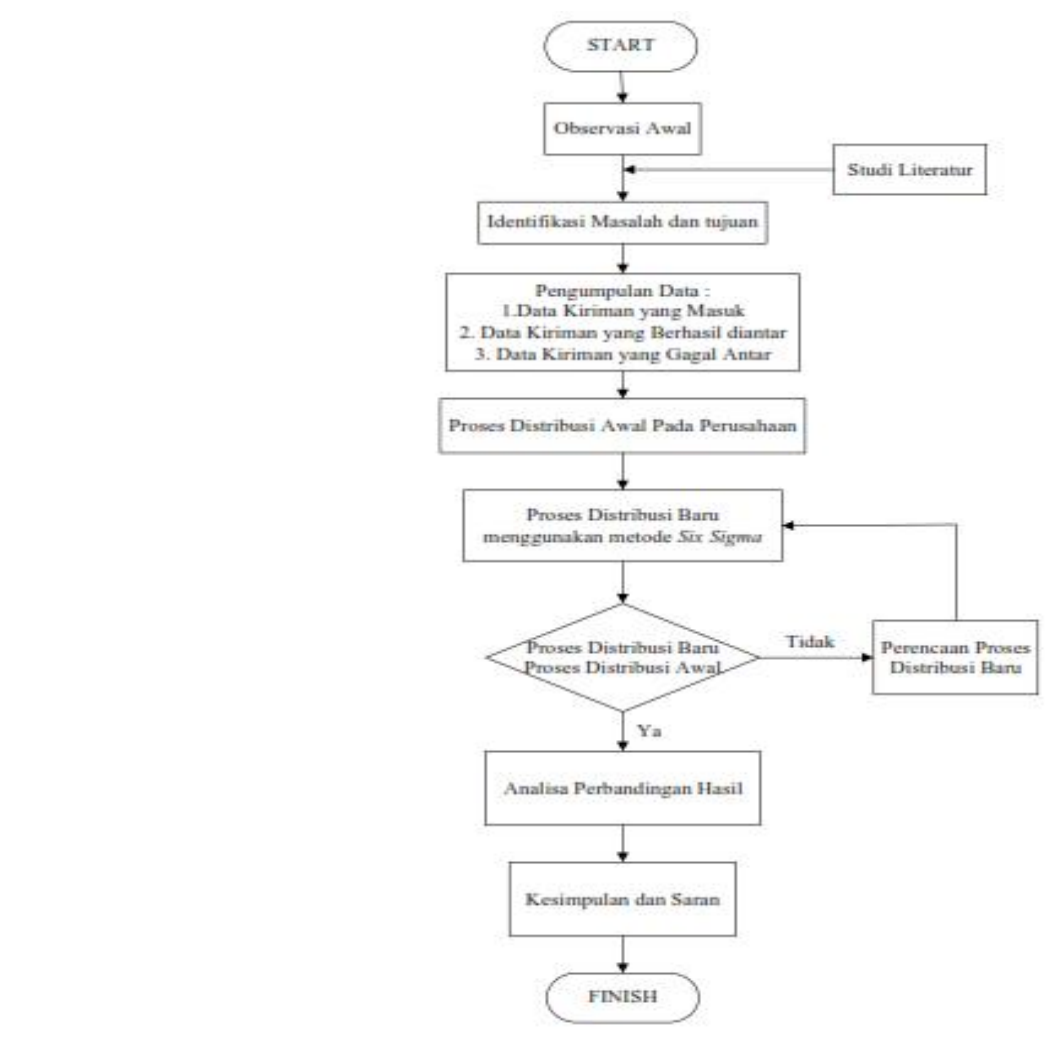

HASIL DAN PEMBAHASAN

Flowchart Penelitian

Tahapan-Tahapan Dalam Distribusi Kiriman Pada PT. Pos Indonesia (Persero) Ambon

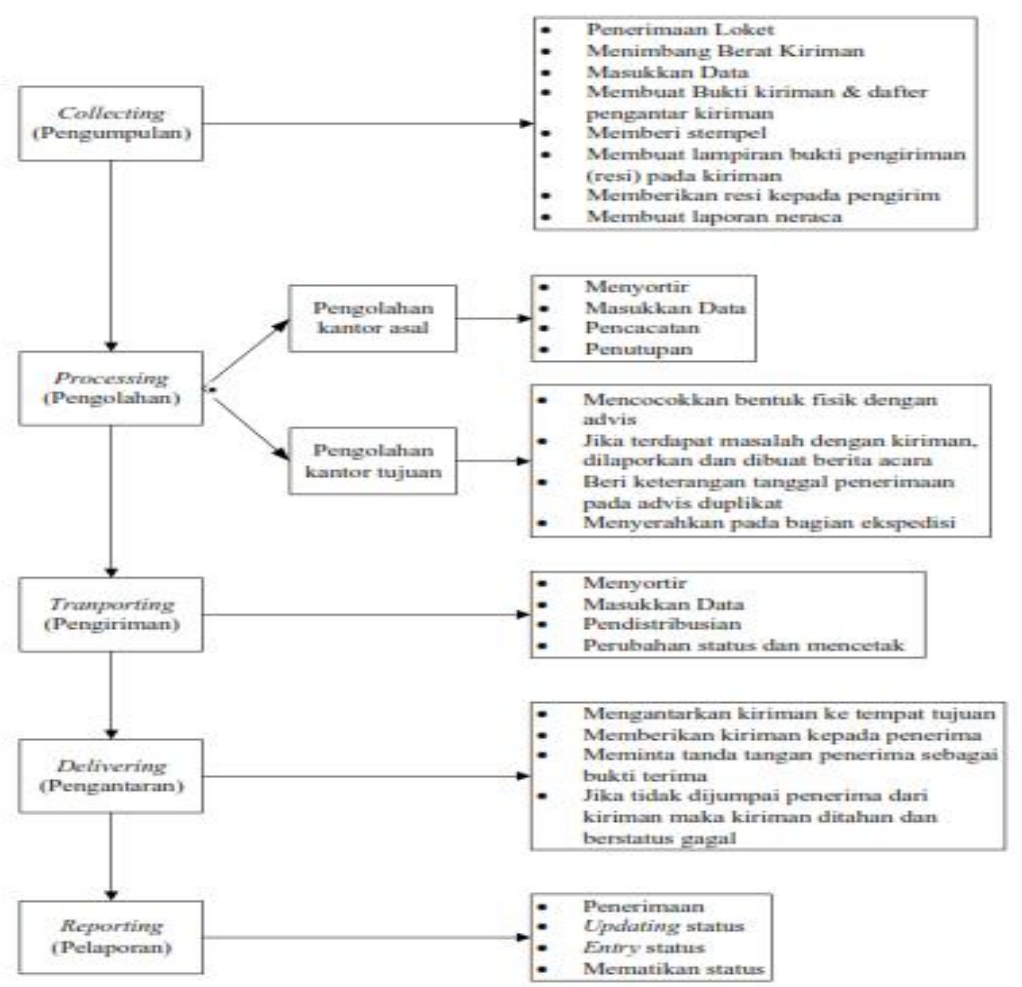

Tahapan Distribusi Kiriman 
Lokasi Distribusi Kiriman PT. Pos Indonesia (Persero) Ambon

Data Lokasi Distribusi Kiriman PT. Pos Indonesia (Persero) Ambon

\begin{tabular}{|c|l|l|}
\hline NO & NAMA KECAMATAN & NAMA KELURAHAN/DESA \\
\hline 1 & SIRIMAU & $\begin{array}{l}\text { Karang Panjang, Amantelu, } \\
\text { Rijali, Uritetu, Batu Meja, } \\
\text { Honipopu, Ahusen, Batu Gajah, } \\
\text { Batu Merah, Galala, Hative }\end{array}$ \\
\hline 2 & Nusaniwe & $\begin{array}{l}\text { Silale, Waihaong, urimessing, } \\
\text { Mangga Dua Wainitu, } \\
\text { Kudamati, Amahusu, Benteng, }\end{array}$ \\
\hline 3 & Baguala & Halong, Lateri \\
\hline
\end{tabular}

\section{Metode Six Sigma}

\section{A. Define (Definsi)}

PT. Pos Indonesia (Persero) Ambon terkhususnya dibagian ekspedisi telah menetapkan SWP (standar waktu penyerahan) yang sebagai target dalam melakukan distribusi kiriman oleh para petugas antaran yang bekerja dibagian ekspedisi. Dari hasil penelitian yang didapat bahwa dibagian ekpedisi PT. Pos Indonesia (Persero) Ambon belum mencapai target kerja yang ditetapkan. Terdapat banyak kiriman yang diantar tidak sesuai dengan target SWP. Hal ini dapat terlihat dari sampel yang diambil dari bulan Januari-Mei 2018

Data Jenis Produk Distribusi Kiriman Pada Bulan Januari-Mei 2018

\begin{tabular}{|c|c|c|c|c|}
\hline BULAN & JENIS & $\begin{array}{l}\text { JUMLAH } \\
\text { KIRIMAN }\end{array}$ & BERHASIL & GAGAL \\
\hline \multirow[t]{3}{*}{ Januari } & Pos & 3867 & 3630 & 237 \\
\hline & Pos Kila & 6785 & 6136 & 649 \\
\hline & Pos & 2305 & 1570 & 735 \\
\hline \multirow[t]{3}{*}{ Februari } & Pos & 2629 & 2513 & 116 \\
\hline & Pos Kila & 8790 & 7988 & 802 \\
\hline & Pos & 6202 & 5675 & 527 \\
\hline \multirow[t]{3}{*}{ Maret } & Pos & 5290 & 5181 & 109 \\
\hline & Pos Kila & 8312 & 7454 & 858 \\
\hline & Pos & 7309 & 6395 & 914 \\
\hline \multirow[t]{3}{*}{ April } & Pos & 6786 & 6685 & 101 \\
\hline & Pos Kila & 9244 & 8267 & 977 \\
\hline & Pos & 7806 & 6645 & 1161 \\
\hline \multirow[t]{3}{*}{ Mei } & Pos & 3098 & 3005 & 93 \\
\hline & Pos Kila & 6712 & 5781 & 931 \\
\hline & Pos & 5375 & 4665 & 710 \\
\hline \multicolumn{2}{|l|}{ Total } & 90510 & 81590 & 8920 \\
\hline
\end{tabular}

Data Distribusi Kiriman Pada Bulan Januari-Mei 2018

\begin{tabular}{|c|c|c|c|c|c|c|}
\hline \multirow[b]{2}{*}{ Bln } & \multirow{2}{*}{$\begin{array}{l}\text { Jumlah } \\
\text { Kiriman }\end{array}$} & \multirow[b]{2}{*}{ Berhasil } & \multicolumn{3}{|c|}{ Jenis Gagal/Cacat } & \multirow{2}{*}{$\begin{array}{c}\text { Jumlah } \\
\text { Gagal/ } \\
\text { Cacat }\end{array}$} \\
\hline & & & AU & SS & KK & \\
\hline JAN & 12957 & 11336 & 1254 & 108 & 259 & 1621 \\
\hline FEB & 17621 & 16176 & 1252 & 101 & 92 & 1445 \\
\hline MAR & 20911 & 19030 & 1650 & 143 & 88 & 1881 \\
\hline APR & 23836 & 21597 & 1959 & 163 & 117 & 2239 \\
\hline MEI & 15185 & 13451 & 1467 & 105 & 162 & 1734 \\
\hline TOTAL & 90510 & 81590 & 7582 & 620 & 718 & 8920 \\
\hline
\end{tabular}


Tabel diatas menunjukkan jenis kecacatan yang terjadi selama proses distribusi kiriman yaitu; antar ulang (AU), salah salur (SS) dan kirim kembali (KK). Persentasi dari jumlah kecacatan yang terjadi dapat terlihat pada tabel berikut.

Kecacatan Dalam Distribusi Pada Bulan Januari-Mei 2018

\begin{tabular}{|l|c|c|c|c|}
\hline Jenis Cacat & $\begin{array}{c}\text { Jumlah } \\
\text { Cacat }\end{array}$ & $\begin{array}{c}\text { Juml } \\
\text { ah }\end{array}$ & $\begin{array}{c}\text { Persentase } \\
\text { Dari }\end{array}$ & $\begin{array}{c}\text { Persentas } \\
\text { e }\end{array}$ \\
\hline Antar Ulang & 7582 & 75 & 8 & 8 \\
\hline Kirim & 7 & 83 & 8 & 93 \\
Kembali & 1 & 00 & 7 & $100 \%$ \\
\hline Salah Salur & 6 & 89 & 10 & - \\
\hline Total & 8920 & - & & 7 \\
\hline
\end{tabular}

\section{B. Measure (Pengukuran)}

1. Menentukan Nilai DPO, DPMO dan Nilai Sigma

$>$ Perhitungan nilai DPO, DPMO dan Sigma pada bulan Januari 2018

$\mathrm{DPO}=\frac{\text { Banyaknya cacal yang ditemukan }}{\text { (Banyaknya unit yang diper ksa } \times \text { [:I(2) }}$

$\mathrm{DPU}=\frac{1.621}{12.95 / \mathrm{X3}}=0,3 / 2318$

$\mathrm{DPMO}=\mathrm{DPO} X 1.000 .000=0,375318 \times 1.000 .000=375.318,4$

Nilai Sigma $=$ NORMSINV $((1.000 .000-$ DPMO $) / 1.000 .000)+1,5$

$=$ NORMSINV $((1.000 .000-375318,4) / 1.000 .000)+1,5$

$=1,817799907=1,81$

$>$ Perhitungan nilai DPO, DPMO dan Sigma pada bulan Februari 2018

$\mathrm{DPO}=\frac{\text { Banyaknya cacai yang ditemukan }}{\text { (Banyaknya unit yang dperiksa } \times \text { CTQ })}$

$\mathrm{DPO}=\frac{1.445}{17.621 \times 3}=0,246013$

$\mathrm{DPMO}=$ DPO X $1.000 .000=0,246013 \times 1.000 .000=246.013,3$

Nilai Sigma $=$ NORMSINV $((1.000 .000-$ DPMO $) / 1.000 .000)+1,5$

$=$ NORMSINV $((1.000 .000-246013,3) / 1.000 .000)+1,5$

$=2,187089137=2,18$

> Perhitungan nilai DPO, DPMO dan Sigma pada bulan Maret 2018

$\mathrm{DPO}=\frac{\text { Banyalnya cacat yang ditemukan }}{(\text { Banyaknya unit yang dperiksa } \times \text { CTQ })}$

$\mathrm{DPO}=\frac{1.881}{20.911 \times 3}=0,269858$

$\mathrm{DPMO}=$ DPO X $1.000 .000=0,269858 \times 1.000 .000=269.858$

Nilai Sigma $=$ NORMSINV $((1.000 .000-$ DPMO $) / 1.000 .000)+1,5$

$=$ NORMSINV $((1.000 .000-26.9858) / 1.000 .000)+1,5$

$=2,113242603=2,11$

> Perhitungan nilai DPO, DPMO dan Sigma pada bulan April 2018

$\mathrm{DPO}=$ Banyaknya cacat yaug ditemukan

DF $=\overline{\text { (Banyaknya unit yang diperiksa } \times \mathrm{CTQ})}$

$D P O=\frac{2.239}{2.3 .836 \times 3}=0,281801$

DPMO = DPO X 1.000.000 = 0,281801 X 1.000.000 = 281.800, 6

Nilai Sigma $=$ NORMSINV $((1.000 .000-$ DPMO $) / 1.000 .000)+1,5$

$=\operatorname{NORMSINV}((1.000 .000-281.800,6) / 1.000 .000)+1,5$

$=2,077500686=2,07$

$>$ Perhitungan nilai DPO, DPMO dan Sigma pada bulan Mei 2018

$\mathrm{DPO}=\frac{\text { Banyalnya cacat yang ditemukan }}{(\text { Banyaknya unit yang diperiksa } \times \text { CTQ })}$

DPO $=\begin{gathered}1.734 \\ 15.185 \times 3\end{gathered}=0.342575$

DPMO = DPO X 1.000.000 = 0,342575 X 1.000.000 = 342.574,9

Nilai Sigma $=$ NORMSINV $((1.000 .000-$ DPMO $) / 1.000 .000)+1,5$ 
$=$ NORMSINV $((1.000 .000-342.574,9) / 1.000 .000)+1,5$

$=1,905445844=1,90$

Perhitungan nilai DPO, DPMO dan Sigma pada bulan Januari-Mei 2018

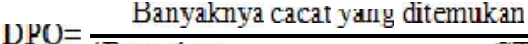

$D P O=\begin{gathered}8.920 \\ 90.510 \times 3\end{gathered}=0.032850$

$\mathrm{DPMO}=\mathrm{DPO} \times 1.000 .000=0,032850 \times 1.000 .000=32.851$

Nilai Sigma $=$ NORMSINV $((1.000 .000-$ DPMO $) / 1.000 .000)+1,5$

$=$ NORMSINV $((1.000 .000-32.851) / 1.000 .000)+1,5$

$=3,34$

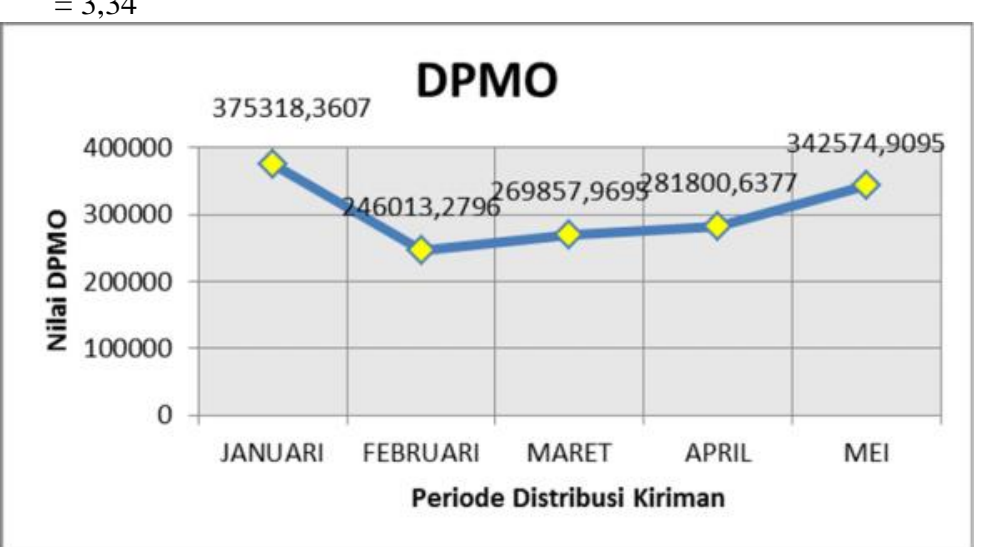

Grafik DPMO Distribusi Kiriman Pada Bulan Januari-Mei 2018

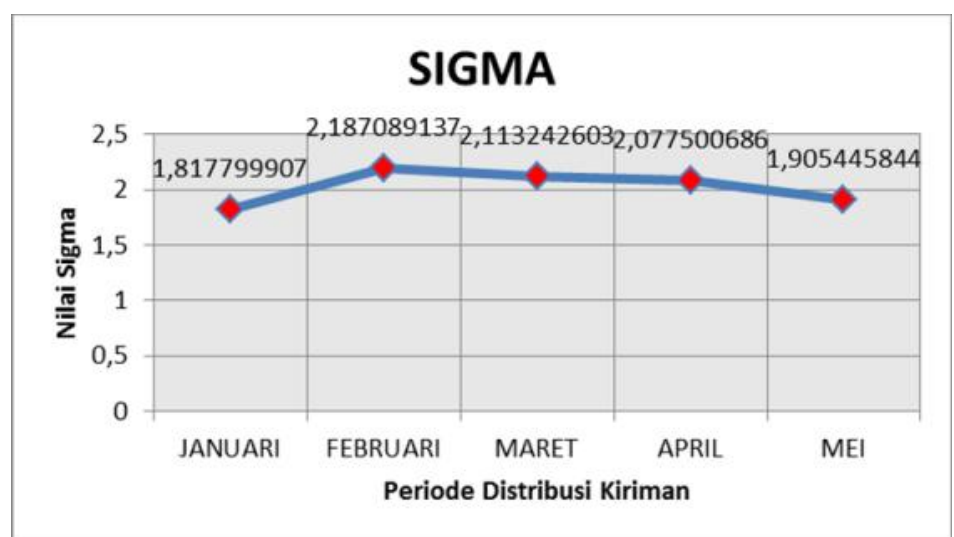

Grafik Sigma Distribusi Kiriman Pada Bulan Januari-Mei 2018

2. Membuat Checksheet

\begin{tabular}{|l|c|c|}
\hline \multicolumn{1}{|c|}{ Jenis Cacat } & Frekuensi & Frekuensi Komulatif \\
\hline Antar Ulang & 7582 & 7582 \\
\hline Kirim & 718 & 8300 \\
\hline Salah Salur & 620 & 8920 \\
\hline Total & 8920 & - \\
\hline
\end{tabular}

Checksheet Pada Bulan Januari-Mei 2018 
3. Membuat Diagram Pareto

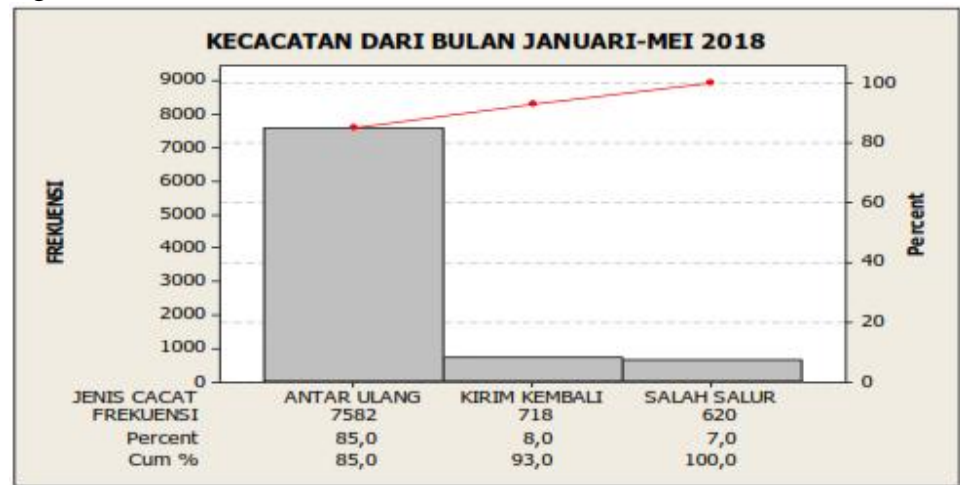

Diagram Pareto Pada Bulan Januari-Mei 2018

\section{Analysis (Analisis)}

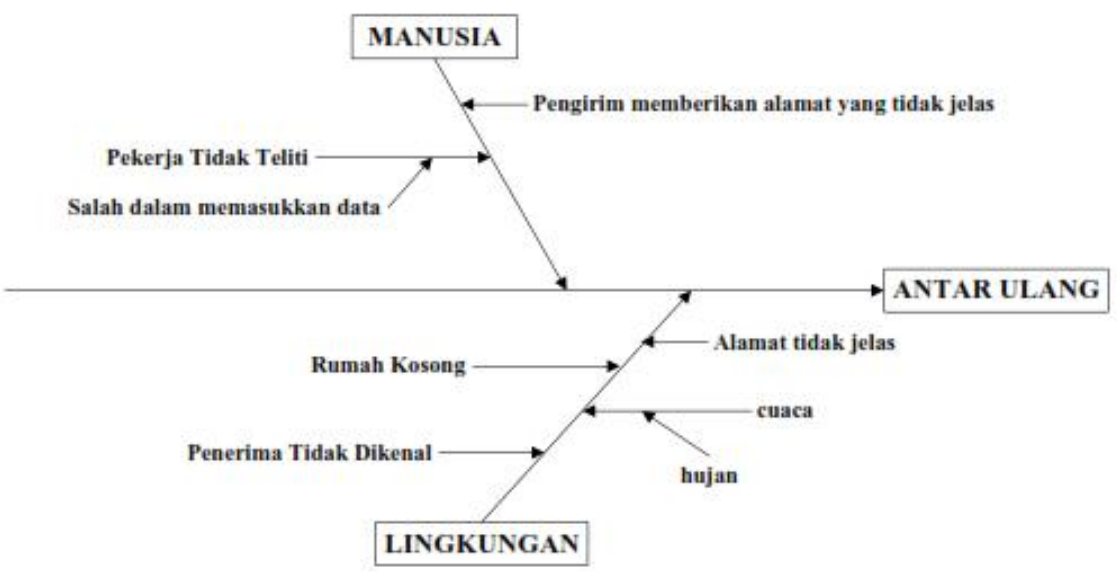

Diagram Sebab Akibat Untuk Jenis Kecacatan Antar Ulang

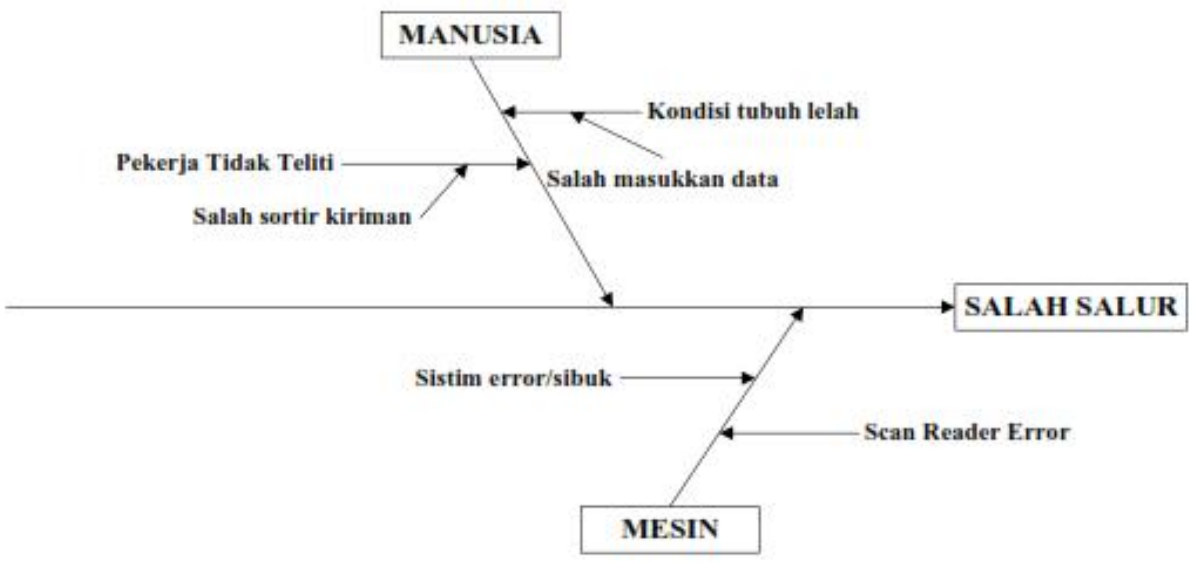

Diagram Sebab Akibat Untuk Jenis Kecacatan Salah Jalur 


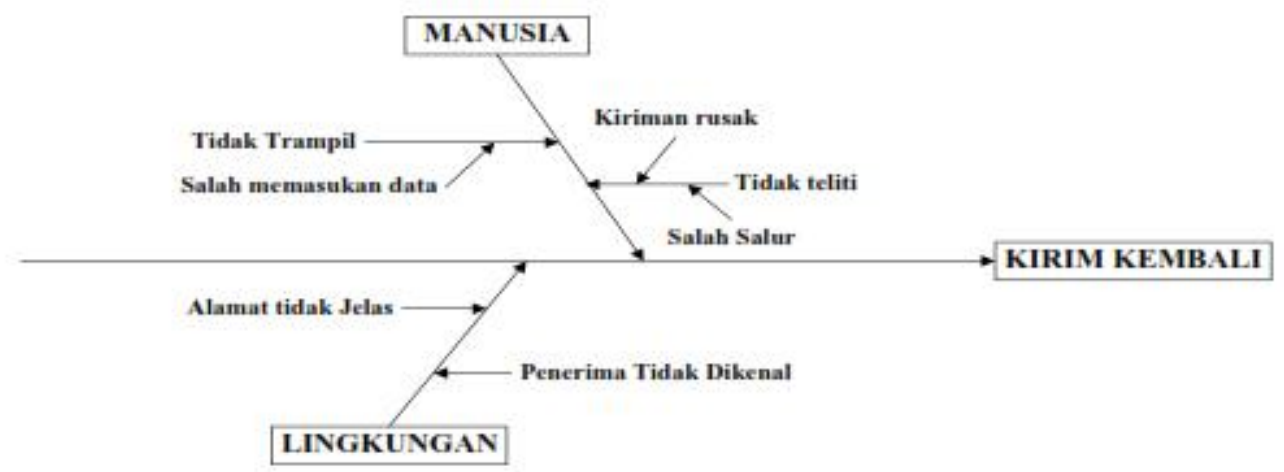

Diagram Sebab Akibat Untuk Jenis Kecacatan Kirim Kembali

\section{Improve (Perbaikan)}

\begin{tabular}{|c|c|c|}
\hline Faktor & Masalah & Solusi Perbaikan \\
\hline \multirow[t]{2}{*}{ Manusia } & $\begin{array}{l}\text { Pengirim memberikan alamat } \\
\text { yang tidak jelas }\end{array}$ & $\begin{array}{l}\text { Memberi usulan kepada petugas } \\
\text { loket agar mengkonfirmasi alamat yang } \\
\text { diberikan pengirim terlebih dahulu } \\
\text { sebelum diproses ke tahap selanjutnya }\end{array}$ \\
\hline & $\begin{array}{l}\text { Pekerja tidak teliti, sehingga } \\
\text { terjadi kesalahan dalam } \\
\text { memasukkan data }\end{array}$ & $\begin{array}{l}\text { Memberi usulan kepada } \\
\text { petugas loket agar lebih teliti } \\
\text { dalam bekerja } \\
\text { Memberi usulan kepada } \\
\text { perusahaan untuk melakukan } \\
\text { training (pelatihan) ulang kepada } \\
\text { pekerja yang selalu melakukan } \\
\text { kesalahan dalam bekerja } \\
\text { Memberi usulan bagi manajer } \\
\text { bagian pelayanan, manajer bagian } \\
\text { puri, dan untuk selalu melakukan } \\
\text { pengontrolan }\end{array}$ \\
\hline \multirow[t]{2}{*}{ Lingkungan } & $\begin{array}{l}\text { Alamat yang tertera pada } \\
\text { kiriman tidak jelas, Rumah Kosong } \\
\text { dan penerima tidak dikenal }\end{array}$ & $\begin{array}{l}\text { Memberi usulan bagi manajer } \\
\text { bagian ekspedisi untuk selalu } \\
\text { melakukan pengontrolan sebelum } \\
\text { petugas antaran mengantarkan kiriman }\end{array}$ \\
\hline & Cuaca Hujan & $\begin{array}{l}\text { Memberi usulan dibagian } \\
\text { MSDM agar memberi fasilitas } \\
\text { yang baik berupa tas antaran yang } \\
\text { dapat digunakan pada cuaca panas } \\
\text { maupun hujan } \\
\text { Memberi usulan pada manajer } \\
\text { bagian ekspedisi agar melakukan } \\
\text { pendisplinan kerja bagi karyawan } \\
\text { yang selalu malas bekerja pada } \\
\text { cuaca hujan. }\end{array}$ \\
\hline
\end{tabular}


Improve (Perbaikan) Pada Kecacatan Salah Jalur

\begin{tabular}{|c|c|c|}
\hline Faktor & Masalah & Solusi Perbaikan \\
\hline \multirow[t]{2}{*}{ Manusia } & Kondisi tubuh lelah & $\begin{array}{l}\text { Memberi usulan kepada } \\
\text { karyawan agar bekerja sesuai dengan } \\
\text { jam kerja, sehingga pada jam istirahat } \\
\text { karyawan dapat beristirahat sejenak. }\end{array}$ \\
\hline & Pekerja tidak teliti & $\begin{array}{l}\text { Memberi usulan kepada } \\
\text { petugas loket, dan pegawai bagian } \\
\text { puri agar lebih teliti dalam menyortir } \\
\text { kiriman } \\
\text { Memberi usulan bagi manajer } \\
\text { bagian pelayanan, manajer bagian } \\
\text { puri, dan untuk selalu melakukan } \\
\text { pengontrolan } \\
\text { Melakukan evaluasi dan } \\
\text { penilaian kinerja karyawan. }\end{array}$ \\
\hline \multirow[t]{2}{*}{ Mesin } & Sistim error & $\begin{array}{l}\text { Memberi usulan agar } \\
\text { diadakan tambahan wifi pada } \\
\text { kantor pos. } \\
\text { Memberi usulan agar fasilitas wifi } \\
\text { yang dimiliki hanya } \\
\text { digunakan bukan untuk kepentingan } \\
\text { pribadi, melainkan hanya untuk } \\
\text { urusan kerja pada saat jam kerja } \\
\text { berlangsung. }\end{array}$ \\
\hline & Alat scan reader error & $\begin{array}{l}\text { Memberi usulan kepada } \\
\text { bagian MSDM untuk segera } \\
\text { mengganti alat scan reader yang } \\
\text { rusak dengan yang baru }\end{array}$ \\
\hline
\end{tabular}

Improve (Perbaikan) Pada Kecacatan Kirim Kembali

\begin{tabular}{|c|c|c|}
\hline Faktor & Masalah & Solusi Perbaikan \\
\hline Manusia & $\begin{array}{l}\text { Tidak Trampil dalam } \\
\text { bekerja, sehingga } \quad \text { melakukan } \\
\text { kesalahan dalam memasukan data. }\end{array}$ & 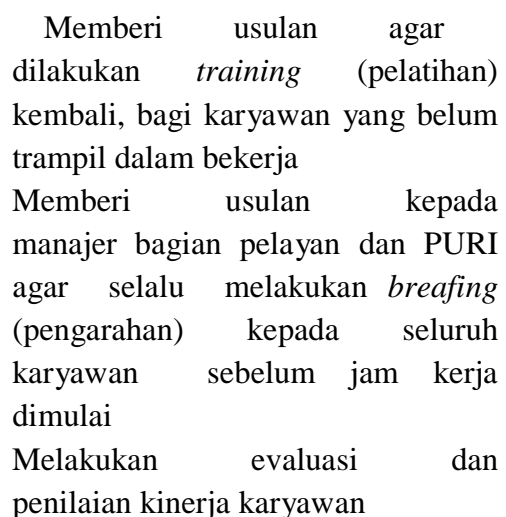 \\
\hline
\end{tabular}




\begin{tabular}{|c|c|c|}
\hline Faktor & Masalah & Solusi Perbaikan \\
\hline & $\begin{array}{l}\text { Pekerja tidak teliti dalam } \\
\text { melakukan packaging pada } \\
\text { kiriman, sehingga kiriman sering } \\
\text { rusak saat tiba di tempat tujuan }\end{array}$ & $\begin{array}{l}\text { Memberi usulan kepada } \\
\text { petugas loket agar lebih teliti } \\
\text { dalam bekerja dan menanyakan } \\
\text { dengan jelas isi dari kiriman } \\
\text { sehingga dapat melakukan } \\
\text { packaging yang lebih aman sesuai } \\
\text { dengan isi kiriman dan tidak } \\
\text { terjadi kerusakaan pada saat } \\
\text { pengiriman. }\end{array}$ \\
\hline & $\begin{array}{l}\text { Pekerja tidak teliti dalam } \\
\text { melakukan penyortiran }\end{array}$ & $\begin{array}{l}\text { Memberi usulan agar } \\
\text { manajer 'melakukan } \\
\text { pengontrolan } \\
\text { Melakukan motivasi kerja agar } \\
\text { pekerja tidak bekerja dibawah } \\
\text { tekanan yang menimbulkan stress, } \\
\text { sehingga tidak teliti dalam bekerja } \\
\text { Melakukan evaluasi dan } \\
\text { penilaian kinerja karyawan }\end{array}$ \\
\hline Lingkungan & $\begin{array}{l}\text { Alama tidak jelas } \\
\text { penerima tidak dikenal }\end{array}$ & $\begin{array}{l}\text { Memberi usulan agar petugas } \\
\text { loket lebih teliti dalam melihat data } \\
\text { yang terdapat pada kiriman, apakah } \\
\text { alamat yang dimiliki }\end{array}$ \\
\hline
\end{tabular}

\section{E. Control (Pengontrolan)}

Setelah perusahaan melakukan tahap perbaikan yang berkelanjutan pada tahap perbaikan, maka langkah selanjutnya dari metode six sigma yaitu dengan melakukan pengontrolan terhadap perbaikanperbaikan yang telah diusulkan. Cara yang akan dilakukan adalah dengan melakukan evaluasi dan penilaian terhadap kegiatan perbaikan yang telah dilakukan

Melakukan pengkoordinasi antara pihak terkait perlu sekali dilaksanakan untuk menjaga keefektifan dan keefesienan seluruh tujuan yang akan dicapai. Setiap jenis kegiatan akan dideskripsikan hal yang harus dilakukan, agar tujuan yang hendak dicapai pada PT. Pos Indonesia (persero) Ambon dibagian ekspedisi yaitu tercapainya target SWP(standar waktu penyerahan), yang ditinjau dari keberhasilan proses distribusi kiriman. Kiriman yang diantarkan harus $100 \%$ terantar kepada penerima dengan aman dan tepat waktu tanpa kendala apapun. Pada setiap tindakannya akan diprioritaskan pada sumber kegagalan yang mempunyai penyebab kegagalan terbanyak, yaitu pada faktor manusia, Lingkungan kemudian dilanjutkan pada faktor-faktor lainnya secara bertahap dan terkendali dengan baik

\section{KESIMPULAN}

1. Dari hasil pengolahan data yang dihitung maka kecacatan yang dimiliki selama 5 bulan dari bulan januari-mei 2018 sebesar 8.920 kiriman dengan CTQ (critical to quality) yang dimiliki yaitu 3, nilai DPMO sebesar 32.851 sehingga nilai sigma yang didapat sebesar 3,34. Jadi, tingkat kegagalan dalam proses distribusi cukup besar karena memiliki nilai sigma yang kecil.

2. Terdapat 3 jenis kegagalan dalam proses distribusi. Antar ulang sebanyak 7.582 kiriman dengan persentasenya $85 \%$, salah salur sebanyak 620 kiriman dengan persentasenya $7 \%$ dan kirim kembali sebanyak 718 kiriman dengan persentasenya $8 \%$. jadi jenis kegagalan yang paling banyak ialah kiriman antar ulang dengan presentasi sebesar $85 \%$.

3. Melalui Metode six sigma terdapat upaya dalam perbaikan proses distribusi kiriman sehingga dapat tercapainya target SWP (standar waktu penyerahan)

\section{DAFTAR PUSTAKA}

Aji Y. W. (2017)., Perkembangan Pt. Pos Indonesia Tahun 1961-1995. Fakultas Ilmu Sosial. Universitas Negeri Yogyakarta. Yogyakarta 
Ariani, Dorothea W. (2003)., Manajemen Kualitas: Pendekatan Sisi Kualitatif. Jakarta: Ghalia Indonesia. Ardiyanta O.(2013). Analisis Strategi Distribusi Untuk Meningkatkan Volume Penjualan pada PT. Salama Nusantara. Universitas Negeri Yogyakarta (UNY). Yogyakarta

Assauri, Sofjan. (1998). Manajemen Produksi dan Operasi. Jakarta: Fakultas Ekonomi Universitas Indonesia.

Bakhtiar S. S. T., dan Hasni R. A. (2013). Analisa Pengendalian Kualitas Dengan Menggunakan Metode Statistical Quality Control (SQC). Miej Journal. 2(1):29-36

Basu, Swasta dan Irawan. (2008)., Manajemen Pemasaran Modern. Yogyakarta: Liberty

Crosby, Philip B. (1979)., Quality is free : The Art of Making Quality Certain, New York : New American Library

Deming, W. Edwards. (1982)., Guide to Quality Control. Cambirdge: Massachussetts institute Of Technology

Dewi S. (2012)., Minimasi Defect Produk dengan Konsep Six Sigma. Jurnal Teknik Industri. 13(1) :43-50

Feigenbauma A. V. (1994)., Total Quality Control, Mc Graw Hill, Singapore

Gaspersz V. (1997)., Manajemen Kualitas, Penerapan Konsep-konsep Kualitas Dalam Manajemen Bisnis Total, PT Gramedia Pustaka Utama, Jakarta

Gaspersz V. (2005), ISO 9001: 2000 and Continual Quality Improvement, PT Gramedia Pustaka Utama, Jakarta

Gaspersz, V. (2005). Sistem Manajemen Kinerja Terintegrasi Balanced Scorecard Dengan Six Sigma Untuk Organisasi Bisnis dan Pemeritah. Jakarta: Gramedia Pustaka Utama.

Kakerissa A. L. (2016)., Manajemen Sumber Daya Manusia. Penerbit Pensil Komunika, Yogyakarta

Kotler, Philip. (1985), Manajemen Pemasaran, Analisis, Perencanaan, Implementasi dan Pengendalian, (Terjemahan), Jakarta : Salemba Empat, Printice Hall, Edisi Indonesia.

Montgomery, Douglas C., (2001)., Introduction to Statistical Quality Control, $4^{\text {th }}$ Edition, John Wiley \& Sons, Inc., New York

Nasution, M. N. (2005)., Manajemen Mutu Terpadu: Total Quality Management, Edisi Kedua, Ghalia Indonesia, Bogor.

Schroeder R. G. Operations.(2007)., Management: Contemporary Concepts and Cases, $3^{\text {rd }}$ ed., Singapore: McGraw Hill

Sulaeman. (2014)., Analisa Pengendalian Kualitas Untuk Mengurangi Produk Cacat Speedometer Mobil Dengan Menggunakan Metode Qcc Di Pt Ins. Jurnal Pasti. 8(1):71-95

Susetyo J. W dan C. Hartanto. (2011)., Analisa Pengendalian Kualitas Dengan Menggunakan Metode Statistical Quality Control (SQC). Jurnal Teknologi. 4(1):61-53

Taguchi, G. (1987)., System of Experimental Design, (Vol. 1-2), UNIPUB/KrausInternational Publication, N.Y: White Plains.

Tjiptono, Fandy, Gregorius Chandra dan Dadi Adriana. (2008)., Pemasaran Strategik. Andi, Yogyakarta. Tutuhatunewa A., dan Tupan J. M. (2014)., Pengendalian Kualitas. Penerbit Unesa University Press2014, Surabaya 